Meta

Journal des traducteurs

Translators' Journal

\title{
Lexical Cohesion and Translation Equivalence
}

\section{Kazem Lotfipour-Saedi}

Volume 42, numéro 1, mars 1997

Lexicologie et terminologie

URI : https://id.erudit.org/iderudit/004014ar

DOI : https://doi.org/10.7202/004014ar

Aller au sommaire du numéro

Éditeur(s)

Les Presses de l'Université de Montréal

ISSN

0026-0452 (imprimé)

1492-1421 (numérique)

Découvrir la revue

Citer cet article

Lotfipour-Saedi, K. (1997). Lexical Cohesion and Translation Equivalence. Meta, 42(1), 185-192. https://doi.org/10.7202/004014ar

\section{Résumé de l'article}

Selon les grands courants de la linguistique moderne, le texte plutôt que la phrase constitue l'unité de traduction, et toute communication passe inévitablement par le cadre du texte. Parmi les caractéristiques qui contribuent à l'essence d'un texte, et le distinguent du non-texte, la cohésion occupe une place de choix. On définit ici la notion d'équivalent de traduction dans le cadre de la cohésion lexicale. Puis on traite des stratégies lexicales utilisées par l'émetteur en langue source, de la nature du réseau de cohésion et du type de structure sémantique qui existe dans les nœuds lexicaux de ce réseau. On examine enfin l'équivalence de traduction du point de vue des mêmes stratégies lexicales.
Ce document est protégé par la loi sur le droit d'auteur. L'utilisation des services d'Érudit (y compris la reproduction) est assujettie à sa politique d'utilisation que vous pouvez consulter en ligne.

https://apropos.erudit.org/fr/usagers/politique-dutilisation/ 


\title{
LEXICAL COHESION AND TRANSLATION EQUIVALENCE
}

\author{
K. LOTFIPOUR-SAEDI \\ University of Tabriz, Tabriz, Iran
}

\begin{abstract}
Résumé
Selon les grands courants de la linguistique moderne, le texte plutôt que la phrase constitue l'unité de traduction, et toute communication passe inévitablement par le cadre du texte. Parmi les caractéristiques qui contribuent à l'essence d' un texte, et le distinguent du nontexte, la cohésion occupe une place de choix. On définit ici la notion d'équivalent de traduction dans le cadre de la cohésion lexicale. Puis on traite des stratégies lexicales utilisées par l'émetteur en langue source, de la nature du réseau de cohésion et du type de structure sémantique qui existe dans les nouds lexicaux de ce réseau. On examine enfin l'équivalence de traduction du point de vue des mêmes stratégies lexicales.
\end{abstract}

\begin{abstract}
According to modern trends in linguistics, a text rather than a sentence is the unit of communication, and communication and negotiation of meanings in human verbal transactions is achieved within the framework of a text. Among the features which contribute to the texture of a text and distinguish it from a non-text, cohesion has been argued to be an important one. Halliday and Hasan (1976) have described different types of cohesion (grammatical, lexical and conjunction). In this paper we would like to define the notion of Translation Equivalence (TE) in terms of lexical cohesion. The type of lexical strategies employed by the $S L$ discourse producer, the nature of the cohesive network (predictive, prospective as well as retrospective) created by such strategies and the type of semantic structures which exist among the lexical nodes in this network will first be characterized. Then the TL equivalent text will be examined in terms of similar lexical strategies.
\end{abstract}

\section{INTRODUCTION}

Based on my discussion of the notion of translation equivalence (cf. LotfipourSaedi 1990, 1992a), this paper will focuss on the notion of texture with special reference to lexical cohesion, the way it contributes to the texture of a text and the translator's task in preserving the lexical cohesion of the SL text. For a practical demonstration of the notion of lexical cohesion, an English text will first be analyzed in terms of the mode of lexical collocation adopted by the author, and the cognitive and aesthetic function such a mode would have on the reader. Subsequently implications will be drawn as to the necessity for the translator to observe the SL mode of lexical collocation.

\section{DIMENSIONS OF TE}

Various definitions have been fiven for translation and translation equivalence. These have been defined in terms of equivalence of meaning, function, effect, even of form. We have chosen a comprehensive framework for the characterization of these notions and have accordingly defined the translator's task as "attempts to create the conditions under which the SL author and the TL reader can interact with one another." Within this discoursal framework, we have introduced seven dimensions of TE: vocabulary, structure, texture, degree of indirection, language variety, cognitive effect and aesthetic effect (cf. Lotfipour-

Meta, XLII, 1, 1997 
Saedi 1992a). We have already argued that these are not to be considered as conditions for TE, but rather as dimensions of TE principles whinh guide the translator (cf. LotfipourSaedi 1996). Texture is one of these dimensions which will be focused on in this paper. Four components have been listed for texture: thematization strategies, schematic structures, cohesion, and paralanguage. Thematization strategies refer to the choice of elements to stand as the theme of each sentence, during the textualization process. Any variations in this would certainly affect the discourse comprehension process. Schematic structures refer to the overall arrangement and macro-structure of the text, which would also affect the comprehension process. By paralanguage we mean the prosodic (speech) features (e.g. intonation and stress patterns) and typographic (writing) features (e.g. underlining, italicizing) which, by creating contrasts among the elements within a text, would contribute to the text-ness of a text. Lastly, cohesion is defined as a semantic concept referring to "relations of meaning that exist within the text, and that define it as a text" (Halliday and Hasan 1976 : 4). These authors have classified the cohesive devices into the three major categories of grammatical cohesion, lexical cohesion and conjunction. We shall look at lexical cohesion in more detail in this study, discussing its implications for TE.

\section{LEXICAL COHESION AND ITS CONTRIBUTION TO TEXTURE}

Halliday and Hasan (1976) and Halliday (1985) talk of two types of lexical cohesion: reiteration and collocation. They define reiteration as follows (1976:278):

Reiteration is a form of lexical cohesion which involves the repetition of a lexical item, at one end of the scale; the use of a general word to refer back to a lexical item, at the other end of the scale; and a number of things in between the use of a synonym, near-synonym, or superordinate.

The fact that the notion presented by the lexical items at a point in the textual presentation would somehow repeat the notions presented earlier in the same text would constitute a semantic network across the text contributing to its cohesion. In the following example:

Accordingly [...] I took leave, and turned to the ascent of the peak. The climb is perfectly easy... (Halliday and Hasan 1976 : 278)

The word the climb would reiterate the notion presented by the word the ascent in the previous sentence.

Halliday and Hasan (1976 : 285) define collocation" "as the following, whose meaning relation is not easy to classify in systematic semantic terms: laugh...joke, blade...sharp, ill...doctor", the cooccurrence of which creates a cohesive effect across the text. But as they note $(1976: 286)$, this cohesive effect "depends not so much on any systematic semantic relationship as on their tendency to share the same lexical environment, to occur in collocation with one another." They add that, any two lexical items having similar patterns of collocation that is, tending to appear in similar contexts, will generate a cohesive force if they occur in adjacent sentences.

Both of these cohesive devices would naturally contribute to the texture of the text involved. But we would like to concentrate on the correlation between the type of lexicalization strategies employed in these two cohesive agents and the nature of their textual function. The degree to which reiteration and collocation contribute to the textual cohesion would vary depending on the choices the text producer opts for from the lexical system. In the case of reiteration, Halliday and Hasan (1976:278) refer to different types of lexical relationship between the reiterated and reiterating elements in the text given above as follows: 


\begin{tabular}{|l|l|l|}
\hline \multicolumn{1}{|c|}{ reiterated element } & \multicolumn{1}{|c|}{$\begin{array}{c}\text { types of lexical } \\
\text { relation between the two }\end{array}$} \\
\hline ..the ascent & $\begin{array}{l}\text { (a) the ascent } \\
\text { (b) the climb } \\
\text { (c) the task } \\
\text { (d) the thing } \\
\text { (e) it }\end{array}$ & $\begin{array}{l}\text { a synonym } \\
\text { a superordinate } \\
\text { a general noun } \\
\text { a reference item }\end{array}$ \\
\hline
\end{tabular}

In the case of collocation, too, the type of lexical choices made within each collocational chain would affect the degree to which it contributes to textual cohesion. This effect can also be argued to be the function of the type of lexical relations between the lexical nodes within such chains.

The type of information activated by each node from the reader's background knowledge, the images associated with the lexical choices made, the type of lexical relationship holding between a lexical node and the ones occurring after it would also determine the mode of reader discourse processing. For instance, depending on whether a lexical node is super-ordinate to or a hyponym of the next-coming lexical nodes, the type of cognitive processes activated by each would be top-down and bottom-up respectively; the cognitive effect and the depth of processes involved would be affected. Winter (1977: 2) refers to retrospective and prospective clause-relations across a text produced by the lexical items under the name of anticipation and realization. He notes that the opensystem lexical items "constitute a special vocabulary of context for the clause relations of English;" and says "they are words which can function as special signposts of what a sentence means in sequence with its adjoining sentence." By analyzing the text into various lexical chains and examining the nature of lexical choices in each chain as well as the interplay between the chains, Butt (1988:217) reveals the way "the changing patterns of lexico-grammatical organization produce distinct shifts in the ontological character of the reality constructed by the text" and sees language "not as the mirror of pre-verbal experience, but as the source of the unfolding of events and happenings." In the following section, we shall analyze a text concentrating on the lexical collocational chain and its effect on the texture.

\section{EXAMINING THE LEXICAL COLLOCATION IN A TEXT}

In this section, we shall actually analyze a text looking at a lexical collocational chain contained in it, by examining the semantic relations between the lexical nodes in the chain, investigating the textual function of the lexical choices and discussing the implications for the translation equivalence.

The text (see appendix 1) is a piece of narrative fiction describing the plight of the writer who is apparently shipwrecked, and is now floating with many other people and things in the water. We've used apparently in depicting the setting because the information is not clearly stated in the text, only understood. We've chosen to concentrate on a specific lexical collocation chain which, in our view, is instrumental in helping the reader to arrive at this understanding. In this analyzis, we shall look at: 
(a) the type of semantic relationship between the nodes;

(b) the arrangement of the lexical nodes in the chain and the distance between them in terms of the number of intervening words;

(c) the degree of embeddedness of each lexical node in the textual hicrarchy.

As mentioned above, the lexical chain we chose to focus on is the one mainly involved in the central theme of the text "floating in the water." It consists of 16 lexical nodes as follows: the surface-floating-water-boats-rafts-(boards)-floating-my board-the board-the board-floating lifebelt-boat-boat-boat-boat. We may look at the way each of these nodes would activate the scene in the reader's active working memory: Is the lexical choice a superordinate one activating a macro-scene in the light of which the subsequent ones can be accommodated: top-down processing, or a choice which activates a minor aspect of a scene placing the reader in an uncertain position in relation to the scene depicted, which he cumulatively modifies in the light of the subsequent scenes: bottom-up processing? What type of semantic relationship exists between the nodes? In this regard, we can classify the lexical items contained in the chain into five semantic fields as follows:

\begin{tabular}{|l|l|}
\hline \multicolumn{1}{|c|}{ Semantic field } & \multicolumn{1}{c|}{ Lexical item } \\
\hline 1 & surface-water \\
\hline 2 & floating-floating-floating \\
\hline 3 & boats-boats-boats-boats-boats \\
\hline 4 & rafts-boards-my board-the board-the board \\
\hline 5 & life-belt \\
\hline
\end{tabular}

Table 1

Thus the whole lexical chain consists of only five semantic nodes in terms of the semantic fields involved, most of the nodes extending their textual domain through reiteration. The reiteration strategies employed are mostly direct repetition with only two variations: one in SF1 - surface water (the former denoting a specific physical dimension of the latter), and the other in SF4 - rafts boards (a co-hyponymy relationship). All these semantic fields belong to the macro-field of floating in water. The relationship between each of the semantic fields and this macro-field is a direct one except for the SF4 and 5. In SF4, the relationship between board and the macro-field is indirectly established in light of its local textual collocation with items like boats. The relationship between lifebelt (SF5) and the macro-field is more indirect and its introduction into the chain widens the scope of the meaning potentials in the text. The fact that such an element is embedded in the "I don't know whether" clause (line 20) contributes more to the plight scene.

Of special interest in terms of the textual function of these lexical choices is the way the choices from these five semantic fields are arranged and distributed in our lexical chain. In this arrangement, we looked at two issues (i) the way the choices from each semantic field are interspersed in the whole chain, and (ii) the distance between the nodes in terms of the number of words which intervene between them. These two, we speculate, 
would certainly have cognitive effect on the reader. By interspersing the elements from different semantic fields, the writer would enable the reader to cumulatively and imaginatively rebuild the scene targeted, and by varying the modes of reiterating the same scene, the text would guarantee deeper processing. Besides, by varying the inter-node worddistance between one word (as in the case of node number 6) and 55 words (as in node number 10) (see table 2), offering several textual clues at short intervals, on the one hand, and withdrawing them completely over a quite long textual interval, on the other, the writer keeps the reader in suspense. By making him cling to the text, using the available clues for visualizing the scene, this textual strategy of punctuating the reader's discourse process with suspense would certainly decrease the level of determinacy of meaning in the text and increase the reader's options in negotiating meaning thus adding to the imaginative dimension of the message and conferring a literary effect to the text.

Apart from the textual features discussed so far, the degree to which the target lexical chain is embedded in the textual hierarchy would also affect the textual function of the lexical chain. We have characterized the variations in textual strategies in terms of the tripartite dimensions of mode, rank and level (cf. Lotfipour-Saedi 1992b). By level, we mean the degree to which an element is embedded in the textual hierarchy. In our view, by varying the degree of embeddedness of an element, the discourse producer can actually foreground or background that element affecting the cognitive effect of the text. For the purpose of determining the degree of embeddedness of our target lexical chain on the basis of a concrete scale to be used in our attempt at evaluating translation equivalence, we have prepared a scale (see appendix 2). This scale may require some refinements. But we are sure it can have definite applications in critical linguistics.

\begin{tabular}{|c|l|c|c|c|c|}
\hline $\begin{array}{c}\text { Node } \\
\text { Number }\end{array}$ & Lexical item & $\begin{array}{c}\text { Belonging to } \\
\text { the semantic } \\
\text { field }\end{array}$ & $\begin{array}{c}\text { inter-node } \\
\text { word distance }\end{array}$ & $\begin{array}{c}\text { the sentence in } \\
\text { which the node } \\
\text { occurs }\end{array}$ & $\begin{array}{c}\text { degree of } \\
\text { embeddedness }\end{array}$ \\
\hline 1 & the surface & 1 & - & 1 & -3 \\
2 & floating & 2 & 10 & 1 & -9 \\
3 & water & 1 & 21 & 1 & -12 \\
4 & boats & 3 & 4 & 2 & -3 \\
5 & rafts & 4 & 3 & 2 & -6 \\
6 & boards & 4 & 1 & 2 & -7 \\
7 & floating & 2 & 6 & 2 & -5 \\
8 & my board & 4 & 21 & 3 & -7 \\
9 & the board & 4 & 38 & 5 & -8.5 \\
10 & the board & 4 & 55 & 8 & -13 \\
11 & floating & 2 & 137 & 12 & -14 \\
12 & life-belt & 5 & 10 & 13 & -14 \\
13 & boat & 3 & 29 & 16 & -16 \\
14 & boat & 3 & 0 & 16 & -17 \\
15 & boat & 3 & 0 & 16 & -18 \\
16 & boat & 3 & 0 & 17 & -21 \\
\hline
\end{tabular}




\section{LEXICAL COHESION AND THE TRANSLATION EQUIVALENCE}

We've characterized the notion of lexical cohesion and we've actually analyzed a lexical chain central to the theme of a piece of text in terms of the type of semantic relations between the lexical nodes contained in it, the inter-node word distance and the degree to which these nodes are embedded in the textual hierarchy. We've also argued that these textual strategies contribute significantly to the cognitive and aesthetic effect of the text. In the light of our characterization of the dimensions of translation equivalence (see above), we think for a translated text to be equivalent to its SL counterpart in terms of the texture dimension, the translator should observe the textual strategies discussed as well as other textual features. We chose to highlight certain aspects of lexical cohesion not because they are always more important than others, but firstly because the textual arrangements are often neglected in discussions of TE, and secondly because in certain text-types, such as literature-texts, such arrangements assume more important role in establishing the required literary effect. In this study, we wanted to compensate for this by focusing on the discoursal view of $\mathrm{TE}$, on the way textual strategies such as those discussed could contribute to the discoursal effect.

In evaluating a tanslated text to determine the degree to which the translator has managed to maintain the discoursal value intended by the SL text, especially in literaturetexts, lexical cohesion as discussed above can offer critical guidelines. The evaluator may observe the following steps:

(i) determine the main lexical chain(s) central to the theme of the SL text;

(ii) describe the semantic relations between the nodes of the chain(s);

(iii) determine the inter-node distance in terms of the number of intervening words;

(iv) determine the degree to which the chain-members are embedded in the textual hierarchy;

(v) evaluate the nature of translation equivalence by comparing the SL and TL in terms of these textual features.

As we argued above these textual strategies need to be observed especially in the translation of certain text-types because the overall cognitive effect, which is a necessary dimension of TE, is the product of such strategies, and the cognitive structure of the reader of a text can be manipulated by such strategies, among many others.

\section{REFERENCES}

BUTT, D. (1988) : "Ideational Meaning and the "Existential Fabric" of a Poem in Fawcett", R. P. and D. J. Young (Eds), New Developments in Systemic Linguistics. Vol. 2 Theory and Application, Pinter Publishers, pp. 174-218.

HALLIDAY, M. A. K. (1985) : An Introduction to Functional Grammar, Edward Arnolds.

HALLIDAY, M. A. K. and R. HASAN (1976) : Cohesion in English, Longmans.

LOTFIPOUR-SAEDI, K. (1990) : "Discourse Analysis and the Problem of Translation Equivalence", Meta, 35 (2), pp. 389-397.

LOTFIPOUR-SAEDI, K. (1992a) : "Analysing Literary Discourse: Implications for Literary Translation", Meta, 37 (2), pp. 193-203.

LOTFIPOUR-SAEDI, K. (1992b) : "Variations in Textual Strategies and their Psycho-sociological Motivations", paper presented at the XVth International Congress of Linguists (CIL 92), August 1992, University Laval, Quebec City, Canada.

LOTFIPOUR-SAEDI, K. (1996) : "Translation Principles vs. Translator Strategies", Meta, 41 (3), pp. $389-392$.

WINTER, E. O. (1977) : "A Clause-relational Approach to English Texts", Instructional Science, vol, 6, pp. 1-92. 


\section{APPENDIX 1}

1 When I came to the surface I found that I formed part of a large, round, floating island composed of people and debris of all sorts, lying so close together that at first there was not very much water noticeable in between. People, boats, hencoops, chairs, rafts, boards and goodness knows what besides, all floating cheek by jowl. A man with a white face and yellow moustache came and held on to the other end of my board. I did not quite like it, for I felt it was not large enough for two, but I did not feel justified in objecting.

10 Every now and then he would try and move round towards my end of the board. This frightened me; I scarcely knew why at the time (I was probably quite right to be frightened; it is likely enough that he wanted to hold on to me). I summoned up my strength - to speak was an effort - and told him to go back to his own end, so that we might keep the board properly balanced. He said nothing and just meekly went back. After a while I noticed that he had disappeared. I don't know what had happened to him. He may have gone off to a hencoop which was floating near by.

20 I don't know whether he had a life-belt on or not. Somehow I think not. Many people were praying aloud in a curious, unemotional monotone; others were shouting for help in much the same slow impersonal chant : "Boat... boat... boat..." I shouted for a minute or two, but it was obvious that there was no chance of any boat responding, so I soon desisted.

\section{APPENDIX 2}

The Scale for Determining the Degree of Embeddeness of an Element in the Textual Hierarchy

1) Is the element presented in the 1st paragraph of the text?
If yes, give
$\mathrm{O}$ if no, give
$-\mathrm{N}^{*}$

2) Is the element presented in the 1st sentence of the paragraph?
If yes, give
0
If no, give
$-\mathrm{N}^{*}$

3) Is the element presented in the main clause of the clause-complex?
If yes, give
and then go to questions (6)-(10)
If no, go to question (4)

4) Is the element presented in the dependent clause
before the main one
$-1$
as the 1st dependent clause
after the main clause
as the 2 nd dependent clause

after the main clause

$-3$

5) Is the element presented in one of the paratactic clauses within the clause-complex?

$\begin{array}{ll}\text { in clause no } 1 & \text { give } 0 \\ \text { in clause no } 2 & \text { give }-1 \\ \text { in clause no } 3 & \text { give }-2\end{array}$

6) Is the element presented in the NPs of the clause? If yes, go to questions (11), (12)

7) Is the element presented in the VP of the clause? If yes, go to questions (9) and (10)

8) Is the element presented in the Adverbials of the clause?

$$
\text { If yes, go to the question (20) }
$$

9) Is the VP free from embedding?

$$
\text { If yes, give }
$$

0

10) Is the VP embedded?
in that-clause-type embedding
in modal-type embedding
$-1$
in first-verb-type embedding
$-0.5$
in first-verb-type embedding 
11) Is the relevant NP one of those directly associated with the verb of the clause?

If yes, go to the following:

the one before the verb give 0

the one immediately after the verb give -1

the second NP after the verb give -2

in the case of the last two, ask also question (9) and (10)

12) Is the element presented as the HEAD WORD in the NP?

If yes, give

0

If no, go to the next question

13) Is it a single NP?

If yes, give

0

14) Does it consist of many paratactically related NPS?

the first such NP
the 2nd
the third

15) Is the element presented as the MODIFIER or the NP?
If yes, give
$-1$
then ask question (16)

16) Is the relevant modifier the first one in the NP?
If yes, give
If no, give
0

17) Is the element presented as the Qualifier of the NP?

If yes, give
and then move on to question (18)

18) Is the relevant qualifier a prep. + NP type?

If yes, ask (18a)

If no, ask (19)

18a) Is it the first such qualifier? give 0
Is it the 2 nd such qualifier?
give -1

so on

- where in the NP? Go to question (12)

$19)$ Is the relevant qualifier a clause-type one?

If yes, ask (19a)

19a) Is it a full-form qualifying clause?

Is it a short-form qualifying cla

As the verb in the clause, go to questions $(9)$ and (10)

As the NPs of the clause, go to questions (11) and (12)

As the adverbial of the clause give -1 and then go to (20)

20) Is the relevant adverbial element
a full-adverbial clause?
- a short-form adv-clause?
give 0
an adv. phrase?
give -1
give -1

Does the target element belong to

- a VP in the adverbial?

If yes, give 0 and then go to questions (9) and (10)

- an NP in the adverbial?

If yes, give 0 and then go to questions (11) and (12)

- an adv. in the adverbial?

If yes, give -1 and then go to question 20 again.

*' $N$ ' denotes the original number of the element (paragraph, sentence, NP, etc.) in the given structure. 